Volume 10, No.6, November - December 2021

International Journal of Advanced Trends in Computer Science and Engineering

Available Online at http://www.warse.org/IJATCSE/static/pdf/file/ijatcse121062021.pdf

https://doi.org/10.30534/ijatcse/2021/121062021

\title{
Soil Properties Classification Using Support Vector Machine for Raver Tehsil
}

\author{
Vipin Y. Borole ${ }^{1}$, Sonali B. Kulkarni ${ }^{2}$ \\ ${ }^{1}$ Department of Computer Science \& IT, Dr. Babasaheb Ambedkar Marathwada University, Aurangabad, \\ Maharashtra, India, vipin_borole@rediffmail.com \\ ${ }^{2}$ Department of Computer Science \& IT, Dr. Babasaheb Ambedkar Marathwada University, Aurangabad, \\ Maharashtra, India, sonalibkul@gmail.com
}

Received Date : October 10, 2021 Accepted Date : November 12, 2021 Published Date : December 06, 2021

\begin{abstract}
Soil properties are dynamic in nature and different factors are affecting to the soil quality. It is directly consequence on soil productivity and soil fertility. The heavy use of fertilizers, heavy rain fall, various agricultural practices are responsible for soil quality degradation. The soil assessment is require to maintain the soil quality. The spectroscopic techniques using Remote sensing and GIS gives the fast and accurate results as compare to traditional soil testing methods. The present study is conducted for classification of soil physicochemical properties in pre monsoon and post monsoon season. Soil samples are collected where Organic, Chemical and Mixed fertilizers treatments were applied to banana and cotton crops sites from Raver tehsil of Jalgaon district. Total 220 soil specimens are collected in pre monsoon and post monsoon season for two year respectively. ASD FieldSpec4 spectroradiometer device were used for data acquisition in the controlled laboratory environment. Acquired spectral data were processed for conversion in numeric format then various statistical methods were used for quantitative analysis of the physiochemical soil properties. The support vector machine is used for classification of the collected soil samples in pre-monsoon and post-monsoon season and classification were performed on the basis of training and testing datasets. The soil samples are divide in pre-monsoon training, pre-monsoon testing and post -monsoon training and post-monsoon testing class with support vector. The hyper plane is used for separation of pre-monsoon and post-monsoon soil samples. Misclassification rate and Mean Squared Error were calculated in the SVM classification.
\end{abstract}

Key words : Soil properties, pre monsoon, Post monsoon, SVM, Spectroradiometer.

\section{INTRODUCTION}

Soil nutrient management is necessary to maintain the constant or high productivity of agricultural systems as well as good quality soil [1]. The use of different fertilizers is essential for fulfillment of nutrients required for plant growth and increasing productivity of soil. Generally chemical, organic and mixed fertilizers are used in agriculture field. Chemical fertilizers are relatively inexpensive, have high nutrient contents, and are rapidly taken up by plants [2] Though, the use of excess fertilizer can result in a number of problems, such as nutrient loss, surface water and groundwater contamination, soil acidification or basification, reductions in useful microbial communities, and increased sensitivity to harmful insects [3]. Organic manure has a number of deficiencies, including low nutrient content, slow decomposition, and different nutrient compositions depending on its organic materials, compared to chemical fertilizers. However, organic manure has multiple benefits due to the balanced supply of nutrients, including micronutrients, increased soil nutrient availability due to increased soil microbial activity, the decomposition of harmful elements, soil structure improvements and root development, and increased soil water availability [4]. Mixed fertilizers are more expensive because it is a combination of chemical and organic fertilizers. Most studies in agricultural fields have reported that the mixed use of chemical fertilizer and organic manure decreases the damage that can be induced by chemical fertilizers and improves crop productivity [3]. The traditional soil assessment methods are manual and time consuming. The quantitative assessment of soil properties using visible near-infrared shortwave infrared (Vis-NIR-SWIR) spectroscopy has been demonstrated as a fast and non-destructive method [5]. The technique is mainly used in the laboratory, where soil samples are prepared and measured under controlled conditions, and it can be considered as an alternative to traditional analytical techniques [6]. The determination of the spatial extent of soil resources is difficult task at a specific site [7].

Reflectance spectroscopy is a fast, nondestructive analytical method that could be used to predict soil properties. The spectral reflectance data can be alternative to the traditional methods for determining soil properties [17-20]. Hyper spectral reflectance with wavelength between 350 and 2500 $\mathrm{nm}$ of soil samples gives better measured using a spectroradiometer in a laboratory environment [21]. There 
are various statistical methods are applied for process the acquired spectral data. The quantitative analysis were perform for getting the status of soil properties availability. On the basis of quantitative analysis the support vector machine were applied for classification of soil properties in pre monsoon and post monsoon season. The minimum misclassification rate and MSE (Mean Square Error) shows the support vector machine gives better results for classification of soil properties in different season.

\section{MATERIALS AND METHODS}

Soil samples are collected from Raver tehsil of Jalgaon district (Study area) figure 1 where Organic, Chemical and Mixed fertilizers treatments used for banana and cotton crops sites in two different season (Pre monsoon and post monsoon) in year 2018 with GPS locations. The soil samples are collected as per the guideline of soil survey and soil testing, Agriculture Department of Maharashtra Government. Same soil samples are collected in the year 2019 pre monsoon and post monsoon. The appropriate soil sampling and preparation of soil samples methods are used for data collection [10-14].

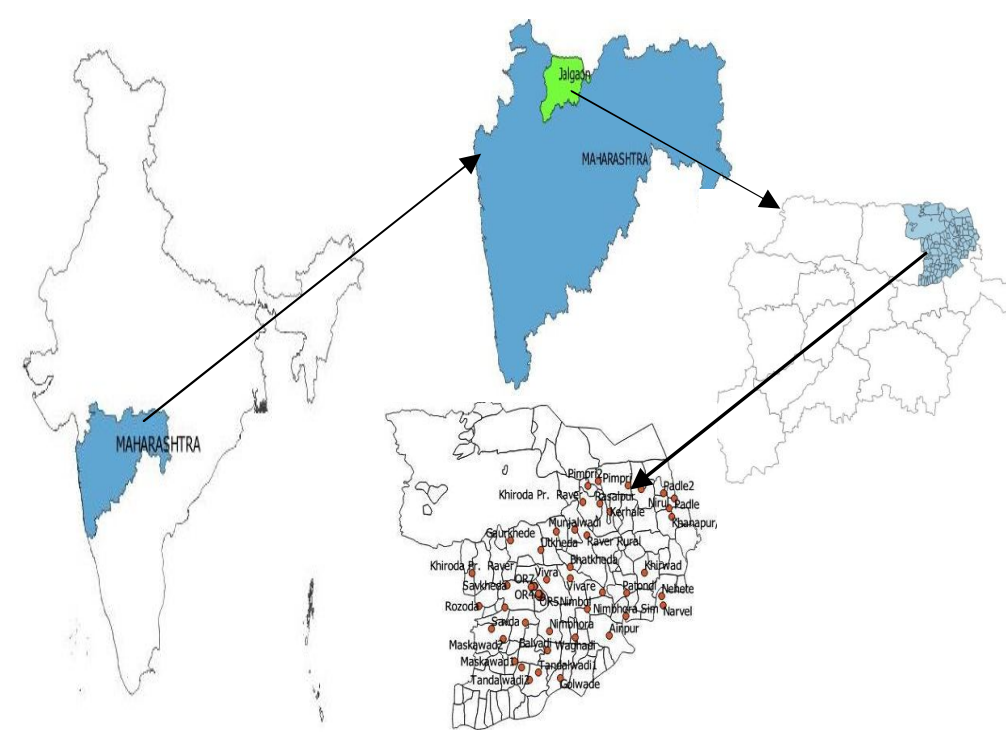

Figure 1: Study area Raver Tehsil of Jalgaon district location map

The dataset of 2018(110 samples) and 110 samples from 2019 in pre monsoon and post monsoon season for each year respectively. Soil samples were measured with the portable Analytical Spectral Devices (ASD) Field Spec4 spectroradiometer with a spectral range of 350-2500 nm. Once every few minutes, the spectrometer was calibrated to spectral reflectance using a standard white reference panel. Each sample was measured ten times, while rotating it $90^{\circ}$ between each reading. These ten readings were later averaged to represent the sample.

\subsection{Data acquisition}

Data acquisition perform using ASD FieldSpec4 Spectroradiometer (Analytical Spectral Devices Inc., Boulder, Colorado, USA) NIR reflectance spectroscopy with a spectral range of 350-2500 nm performed in under controlled lab condition. Once every few minutes, the spectrometer was calibrated to spectral reflectance using a standard white reference panel. Each sample was measured ten times, while rotating it $90^{\circ}$ between each reading. These ten readings were later averaged to represent the sample. The required set up were used for data acquisition [15-18] in Multispectral Research lab, Department of Computer Science \& Information Technology, Dr. Babasaheb Ambedkar Marathwada University, Aurangabad. There are 10 spectral signature are acquired for each samples.

\subsection{Data processing}

The acquired 10 spectral signatures for each samples are processed by applying mean and generate one spectral signature for each sample. The different fertilizers and crop wise mean data were processed. The spectral mean data converted in numeric format using ViewSpecPro software. Numeric data were opened in Microsoft Excel and process the by applying statistical mean methods for quantitative analysis of soil properties on the respective absorption wavelength range. the quantitative analyzed total 220 soil samples were divided into training and testing sets for pre monsoon training, pre monsoon testing and post monsoon training, post monsoon testing.

\section{RESULTS AND DISCUSSION}

Spectral data were acquired using spectroradiometer and processed quantitative data were used for the classification. SVM (Support Vector Machine) classifier used for classification of the collected soil sample in pre-monsoon and post-monsoon season. On the basis of quantitative analysis, the soil properties from collected soil samples are dynamic in different season. The various factors are responsible for alter the soil properties in different season i.e. fertilizer treatments, different agriculture practices, rainfall and irrigation system etc. The collected soil samples quantitative data were divide in pre-monsoon training, pre-monsoon testing and post monsoon training and post-monsoon testing class with support vector. The hyper plane is used for separation of pre-monsoon and post-monsoon soil samples. Misclassification rate and Mean Squared Error were calculated in the SVM classification. The classification were successfully classify the all classes and representation of Misclassification rate and Mean Squared Error in table 1. for each soil properties. 
Table 1: Misclassification rate and MSE of soil properties classification

\begin{tabular}{lcl}
\hline & $\begin{array}{c}\text { Misclassificatio } \\
\text { n Rate }\end{array}$ & MSE \\
\hline Sand & 0.1 & 0.269839 \\
Silt & 0.11 & 0.351525 \\
clay & 0.12 & 0.289725 \\
SOM & 0.1 & 0.289725 \\
Moisture & 0.18 & 0.266681 \\
pH & 0.13 & 0.317109 \\
Carbon & 0.1 & 0.26345 \\
Nitrogen & 0.12 & 0.289725 \\
Phosphorou & 0.14 & 0.282301 \\
s & 0.13 & 0.258881 \\
Potash & & \\
\hline
\end{tabular}

\subsection{Classification using Support Vector Machine} The support vector machine is used for classification of the collected soil samples in pre-monsoon and post-monsoon season.
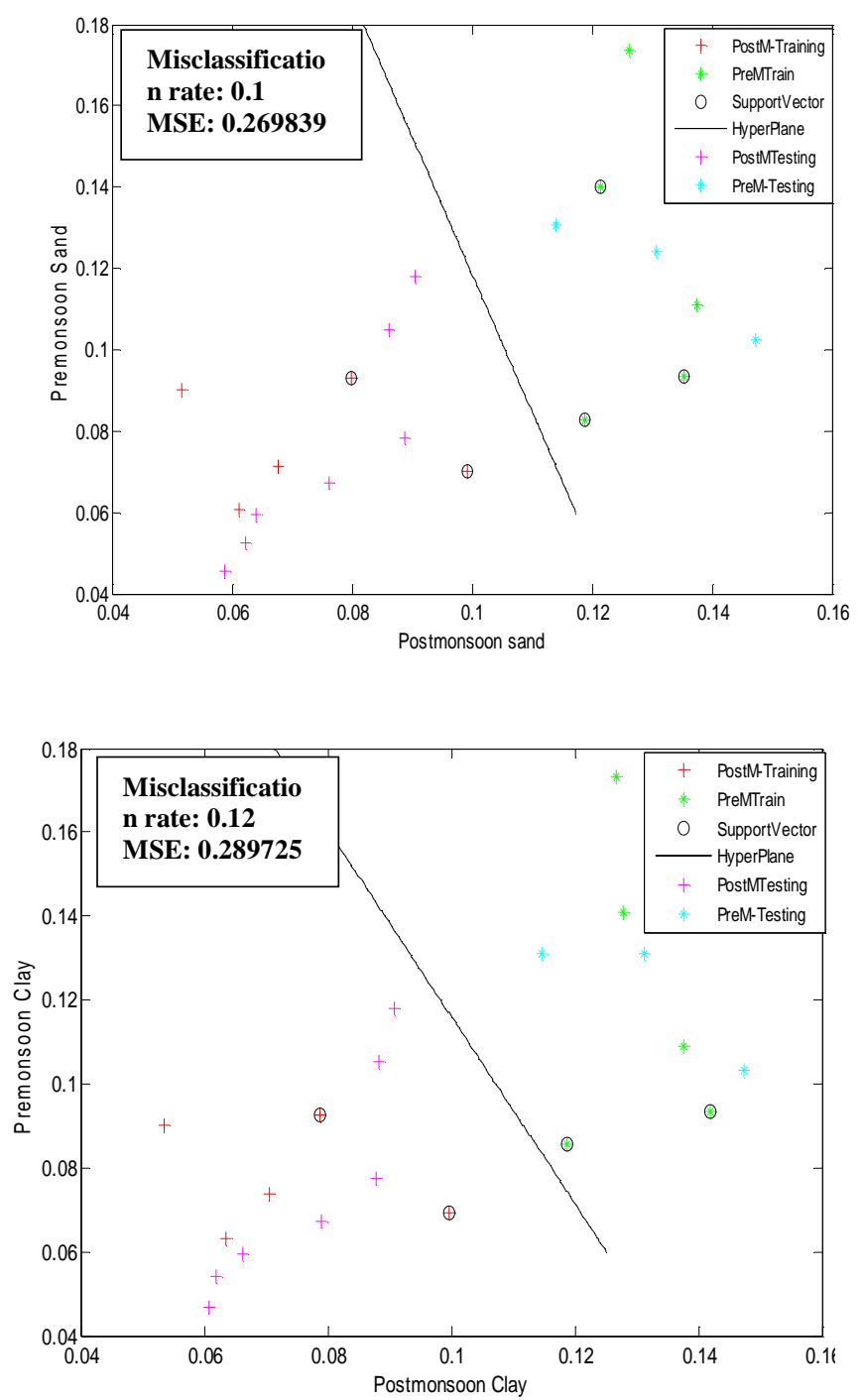
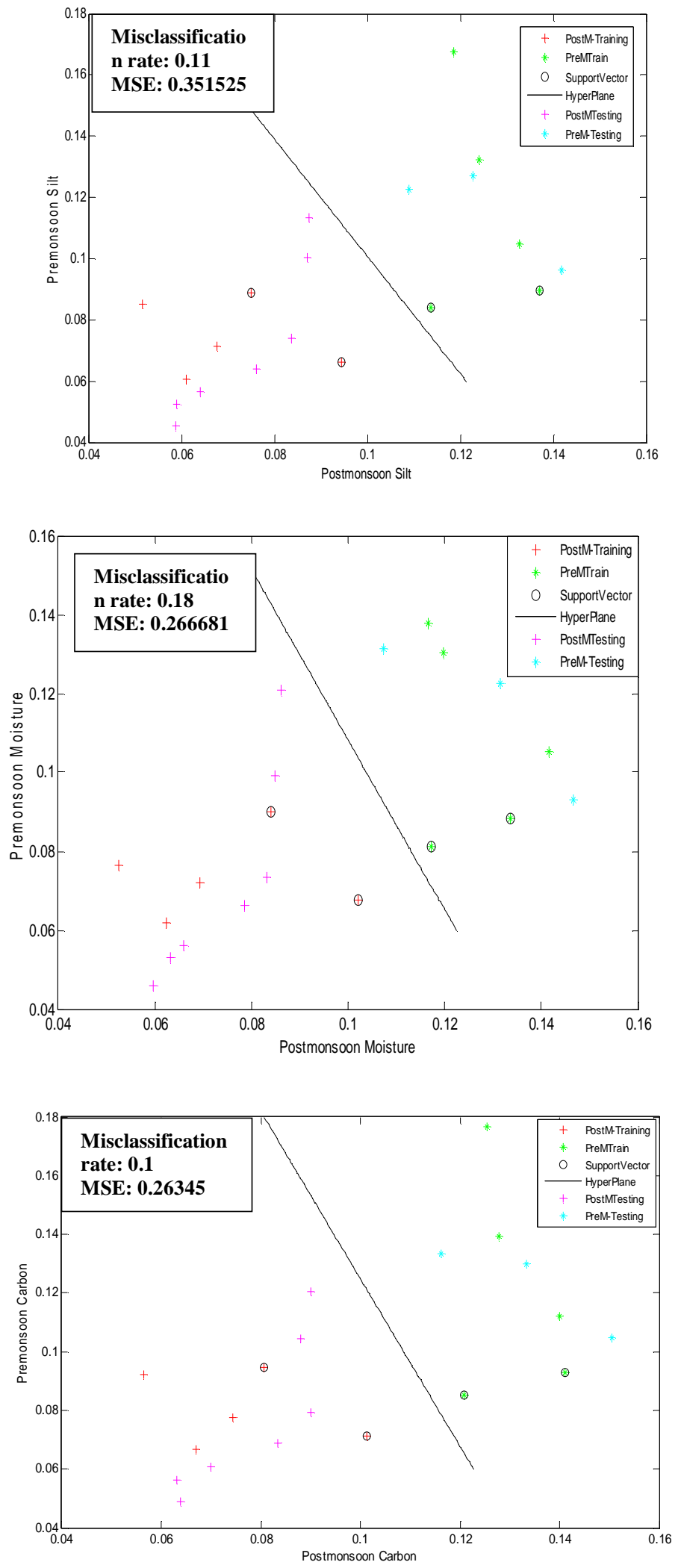

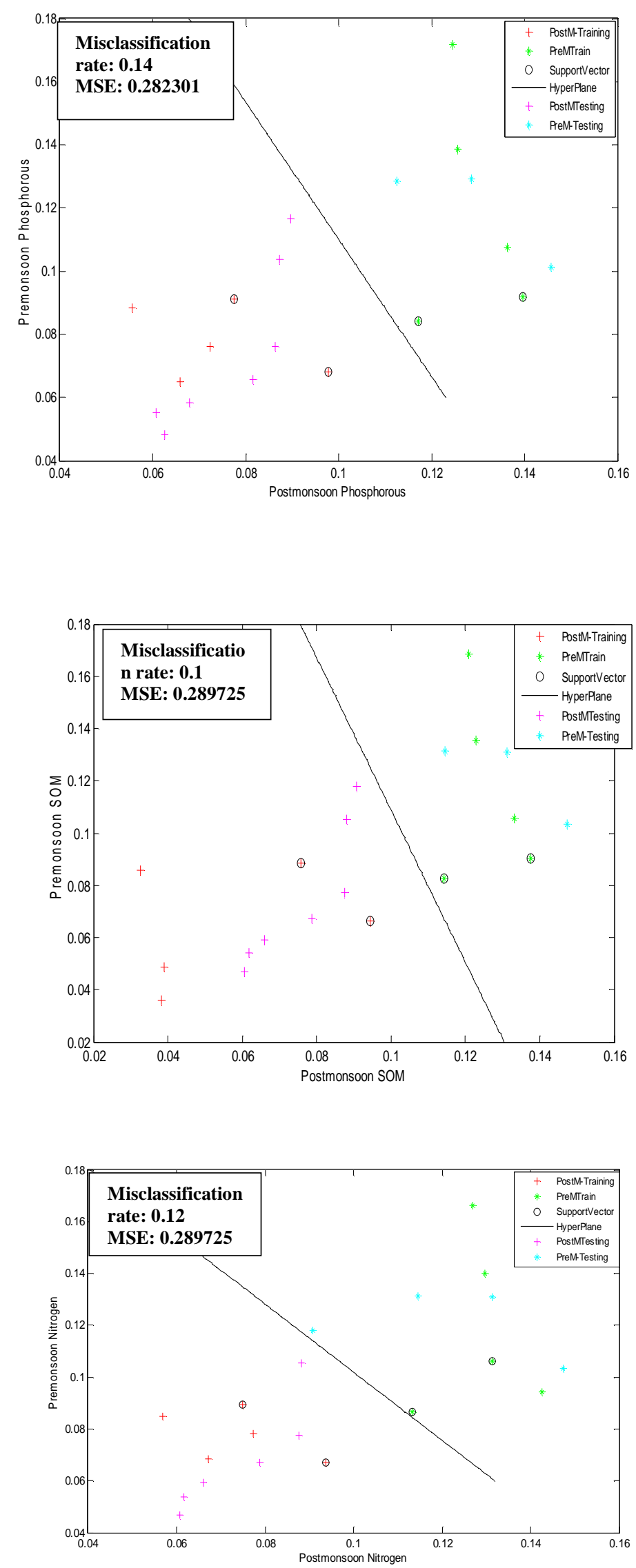
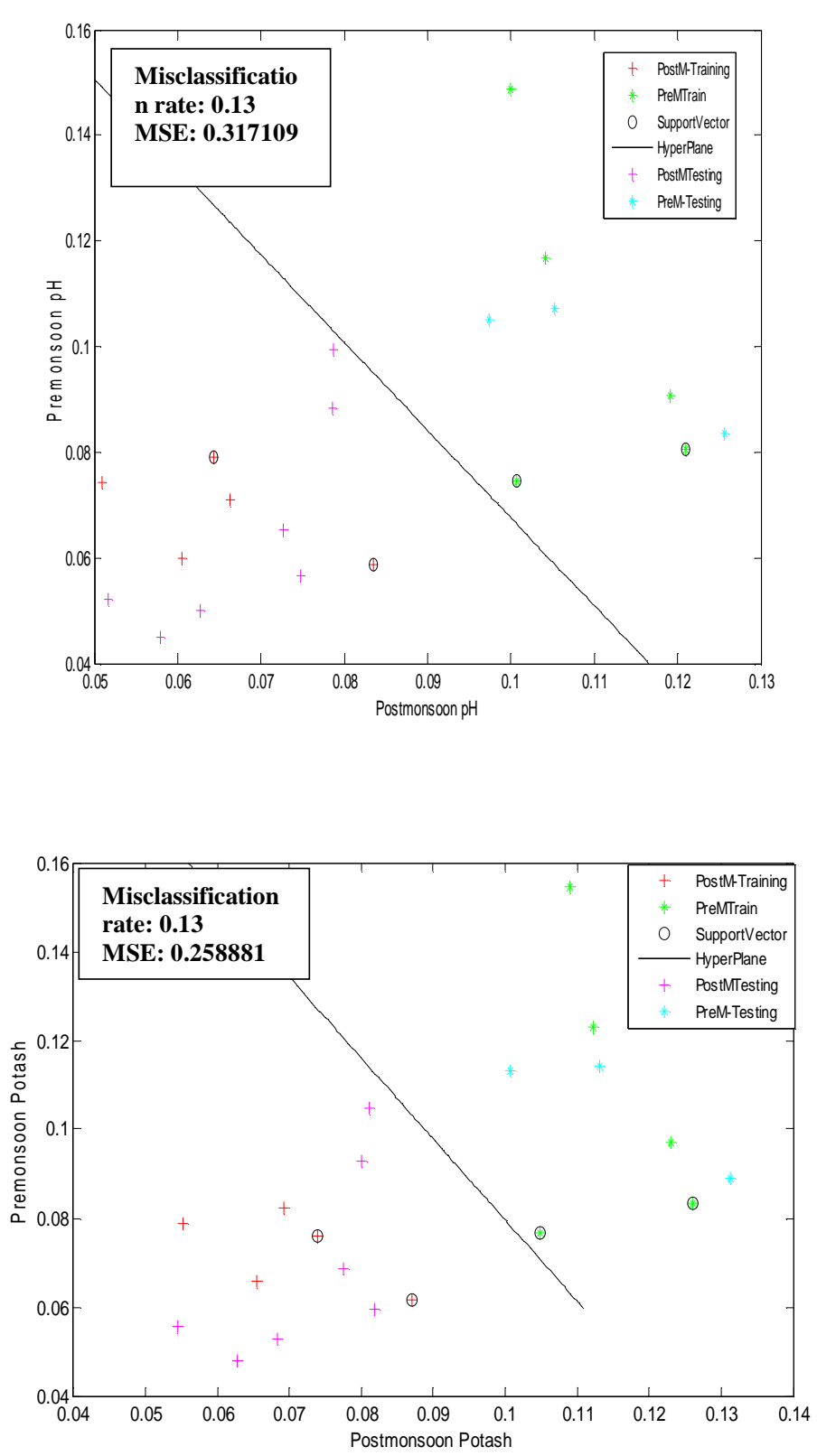

Figure 2: Season wise classification using Support Vector

\section{Machine}

The soil samples are divide in pre-monsoon training, pre-monsoon testing and post monsoon training and post-monsoon testing class with support vector. The hyper plane is used for separation of pre-monsoon and post-monsoon soil samples. Misclassification rate and Mean Squared Error were calculated in the SVM classification. The misclassification rate of overall soil properties are minimum. The minimum misclassification rate is 0.1 and maximum 0.18 it represents the overall classification were successfully classify the all classes. The representation of SVM classifier is shown in figure 2. for each soil properties. 


\section{CONCLUSION}

Reflectance spectroscopy is a fast, nondestructive analytical method that could be used to predict soil properties. The spectral reflectance data can be alternative to the traditional methods for determining soil properties. Hyper spectral reflectance with wavelength between 350 and $2500 \mathrm{~nm}$ of soil samples gives better measured using a spectroradiometer in a laboratory environment. There are various statistical methods are applied for process the acquired spectral data. The quantitative analysis were perform for getting the status of soil properties availability. On the basis of quantitative analysis the support vector machine were applied for classification of soil properties in pre monsoon and post monsoon season. The minimum misclassification rate and MSE (Mean Square Error) shows the support vector machine gives better results for classification of soil properties in different season. It is helpful for classification of soil samples in the assessment of soil properties for long term monitoring.

\section{REFERENCES}

[1] Si Ho Han, Ji Young An, Jaehong Hwang, Se Bin Kim \& Byung Bae Park, "The effects of organic manure and chemical fertilizer on the growth and nutrient concentrations of yellow poplar (Liriodendron, tulipifera Lin.) in a nursery system", Forest Science and Technology, 12:3, 2016, pp.137-143

[2] Liu E, Yan C, Mei X, Zhang Y, Fan T, "Long-Term Effect of Manure and Fertilizer on Soil Organic carbon Pools in Dryland Farming in Northwest China", PLoS ONE, Vol. 8, issue 2, 2013, pp.1-9

[3] Vipin Y. Borole, Sonali B. Kulkarni, "Soil quality assessment for analyzing the effect of chemical fertilizers on agriculture field using Spectroradiometer: A review", International Conference on Electrical, Communication, Electronics, Instrumentation and Computing (ICECEIC), IEEE, 2019

[4] Vipin y. Borole, sonali b.kulkarni, pratibha r. Bhise, "soil properties assessment in surface and Subsurface using spectroradiometer for Raver tehsil of jalgaon district", journal of critical reviews, vol 7, issue 18, aug 2020, pp. 2487-2495

[5] M. Todorova, A. M. Mouazen, H. Lange and S. Astanassova, "Potential of near-infrared spectroscopy for measurement of heavy metals in soil as affected by calibration set size", Springer, Water Air Soil Pollut, vol. 225, No.8, 2036, pp. 1-19, July 2014.

[6] K. Khadse, "Spectral reflectance characteristics for the soils on baseltic terrain of central Indian plateau", J Indian Soc Reomte Sens (Journal of the Indian Society of Remote Sensing), Springer, vol. 40, No. 4, pp. 717-724, Dec 2011.

[7] Vipin Y. Borole, Sonali B. Kulkarni, Pratibha R. Bhise, "Soil spectral signature analysis for influence of fertilizers on two differen crops in raver Tahshil",
International Journal of Recent Technology and Engineering, Volume-8, Issue-3, Sep-2019, pp. 659-663

[8] Vipin Y. Borole, Sonali B. Kulkarni, Pratibha R. Bhise, "Effect of fertilizers on soil properties for different crops in pre-monsoon season using spectroradiometer for Raver tehsil of Jalgaon district", International Journal of Scientific and Technology Research, Volume 9, Issue 2, February 2020, pp. 844-849

[9] Pratibha R.Bhise , Sonali B.Kulkarni, Vipin Y. Borole.," Preprocessing and statistical analysis of soil parameters using conventional laboratory techniques and non-imaging spectral techniques for Vaijapur taluka", International Journal of Recent Technology and Engineering, Volume 8, Issue 2, pp. 3092-3096, July 2019

[10] Vipin Y. Borole, Sonali B. Kulkarni, "Comparative Analysis of Soil Properties for Influence of Fertilizers using Remote Sensing Techniques", International Journal of Computer Applications (0975 - 8887) Volume 174 - No. 21, February 2021, pp. 24-34

[11] Vipin Y. Borole, Sonali B. Kulkarn, "Spectral data analysis methods for soil properties assessment using remote sensing", IOSR Journal of Computer Engineering (IOSR-JCE), Volume 23, Issue 1, Ser. I (Jan. - Feb. 2021), PP 14-18

[12] Bhise Pratibha.R, Kulkarni Sonali.B "Remote Sensing and Data Mining Techniques Applied on Soil Characteristics Data Classification”, IOSR Journal of Computer Engineering (IOSR-JCE), pp. 83-91

[13] P.R. Bhise, S.B. Kulkarni, "Evaluation of Soil Physical/Chemical Parameters for Agriculture Production in Vaijapur Taluka Using VNIR-SWIR Reflectance Spectroscopy", International Journal of Computer Sciences and Engineering, Vol.-6, Issue-12, pp. 43-48, Dec 2018

[14] Vipin Y. Borole, Sonali B. Kulkarn, "Prediction of soil physicochemical properties by Visible and Near-Infrared Diffuse Reflectance Spectroscopy using Partial List Square Regression",International Journal of Creative Research Thoughts, Volume 9, Issue 6, June 2021, pp. 9869- 9878

[15] Pratibha R.Bhise, Sonali B.Kulkarni, "Estimation of Soil Macronutrients From Spectral Signatures Using Hyperspectral Non-Imaging Data", International Conference on Electrical, Communication, Electronics, Instrumentation and Computing (ICECEIC), IEEE, 2019

[16] Pratibha R.Bhise , Sonali B.Kulkarni, "Review on Analysis and Classification Techniques of Soil Study in Remote Sensing and Geographic Information System", International Journal of Emerging Trends \& Technology in Computer Science (IJETTCS), Volume 6, Issue 1, pp.124-138

[17] Pratibha R.Bhise, Sonali B.Kulkarni, Vipin Y. Borole.," Preprocessing and statistical analysis of soil parameters using conventional laboratory techniques and non-imaging spectral techniques for Vaijapur 
taluka", International Journal of Recent Technology and Engineering, Volume 8, Issue 2, pp. 3092-3096, July 2019

[18] Abhay Omprakash Shirale, Vilas Kashinath Kharche, Rupesh Sakharam Zadode, Bharat Prakash Meena, Selladurai Rajendiran, "Soil biological properties and carbon dynamics subsequent to organic amendments addition in sodic black soils", Archives Of Agronomy And Soil Science, Tylor \& Francis group, VOL. 63, NO. 14, Pg. 2023-2034, 2017

[19] Jean-Philippe Gras, Bernard G. Barthes, Brigitte Mahaut, Severine Trupin, "Best practices for obtaining and processing field visible and near infrared (VNIR) spectra of topsoils", Geoderma, ELSEVIER,2014 Pg No. 126-134

[20] Eyal Ben Dor, Cindy Ong, Ian C. Lau, "Reflectance measurements of soils in the laboratory: Standards and protocols", Geoderma, ELSEVIER,2015 Pg No. 112-124 